\title{
Pentalogy of Cantrell with Total Ectopia Cordis and a Major Omphalocele-A Case Report
}

\author{
Arturo Leonardo Delgado, Kopolo Mfuneko Matongo, Bangasa Dumo, Ntsikelelo Mzayiya and Busisiwe Mrara \\ Department of Surgery, Walter Sisulu University/Nelson Mandela Academic Hospital, Umtata 5099, Eastern Cape, South Africa
}

\begin{abstract}
Ectopia cordis (EC) is a rare malformation due to failure of maturation of the midline mesodermal components of the chest and abdomen. It can be defined as $0.1 \%$ of congenital heart diseases, and it could present isolated or could belong to the spectrum of the Pentalogy of Cantrell (PoC), which is a rare congenital disorder first described in 1958 by Cantrell. We are reporting a rare case of total ectopia cordis, associated to a major omphalocele, total agenesis of the sternum, anterior diaphragmatic deficiency, absence of pericardium, and persistence of the Ductus arteriosus, making therefore these features compatible with a full spectrum of the Pentalogy of Cantrell, encouraging us to report this case.
\end{abstract}

Key words: Ectopia cordis, major omphalocele, sternum agenesis, anterior diaphragmatic deficiency, absence of pericardium, persistence of the Ductus arteriosus.

\section{Introduction}

Ectopia cordis (EC) is a rare malformation due to failure of maturation of the midline mesodermal components of the chest and abdomen. It can be defined as $0.1 \%$ of congenital heart diseases, and it could present isolated or could belong to the spectrum of the Pentalogy of Cantrell (PoC). PoC is a rare congenital disorder first described in 1958 by Cantrell. The full spectrum of this syndrome consists of midline supraumbilical abdominal wall defect, defect of the lower sternum, deficiency of the anterior diaphragm, defect in diaphragmatic pericardium and congenital heart disease (Cantrell et al. 1958) [1]. The incidence of EC is sporadic with only 5.5 to 7.9 per 1 million live births (de Rubens Figueroa et al. 2011) [2]. PoC has its origin in embryologic development, resulting from defective formation and differentiation of the ventral mesoderm at about 14 to 18 days of embryonic life [1]. The aetiology is probably sporadic and multi causal transmission, the exact pathogenesis remains unknown. Outcome of PoC with ectopia cordis and congenital heart defect is disastrous [3].

Corresponding author: Arturo Leonardo Delgado, MD, FCS, associate professor, research field: surgery.

\section{Case Report}

We present a neonate 3 hours after birth, through Csection, Apgar 7/10, 6/1, weigh of $3.2 \mathrm{~kg}$. Crying at delivery but central cyanoses, respiratory distress, intubated and ventilated. No sternum, heart outside the chest, no pericardium covering. Intact Omphalocele is about $10 \times 10 \mathrm{~cm}$. Rest of physical exam unremarkable, was done diagnoses of a PoC and complete thoracic ectopia cordis with cephalic orientated cardiac apex, deficiency of the anterior diaphragm, agenesis of the sternum, persistence of the arteriosus duct, left superior cavavein and a major omphalocele, echocardiogram patent ductus arteriosus (PDA). INR 2,67, other blood tests were normal.

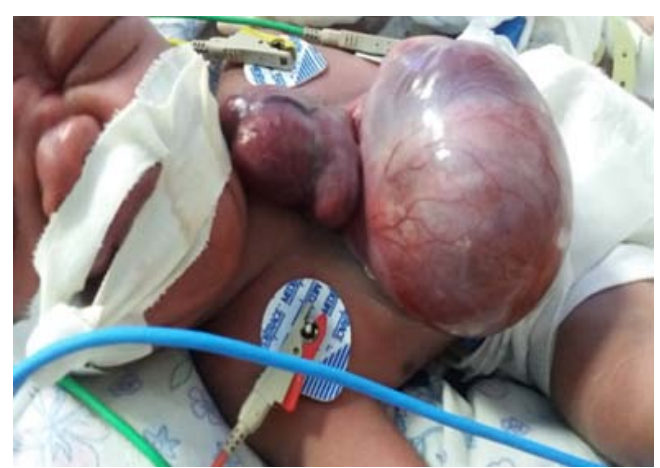

Fig. 1 A 3 hours Neonate, was born with total Ectopia cordis and a major Omphalocele. 


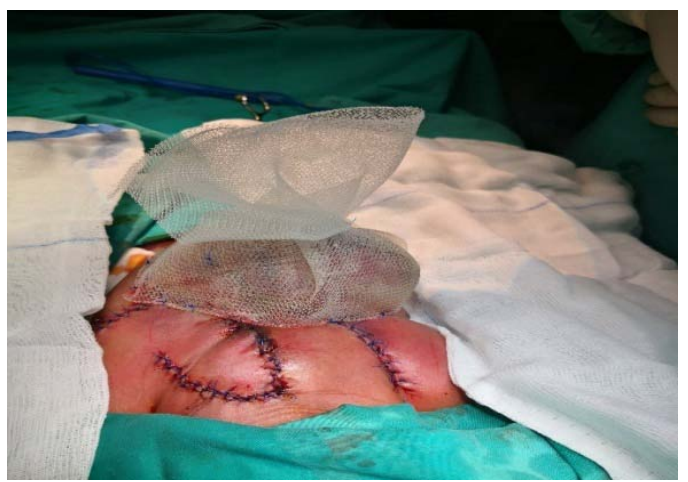

Fig. 2 Operation finished after located the heart into the chest.

After stabilisation the neonate was taken to theatre. In theatre was produced a chest cavity to receive the heart, removing three left costal cartilages and dissecting the left superior vena cava reflecting more to the left. The heart was located with the apex up; after that was covered the ectopia cordis by mesh and cutaneous pedicled flap; the omphalocele, was covered by silver sulfadiazine and located a mesh for a conservative treatment since the big size of it made impossible the surgical correction of the omphalocele.

After operation patients keeping on mechanical ventilation till 12 hours later when the child suffered a cardiac arrest and did not respond to the resuscitation manoeuvres.

\section{Discussion}

PoC including complete thoracic ectopia cordis is a rare congenital disorder of unknown pathogenesis with sporadic incidence [2]. Especially, complete thoracic ectopia cordis in addition to complex heart disease, is known to have poor prognosis [4, 5]. Surgical internalization of the heart into the thoracic cavity is associated with high risk of cardiovascular compromise andischemia [5]. The paucity of survivors with this entity demonstrates the need for extreme caution in preserving hemodynamic stability when the heart is covered, whether the repair is performed as a primary or a staged repair.

\section{Conclusions}

Pentalogy of Cantrell including complete thoracic ectopia cordis is a rare congenital disorder of unknown pathogenesis with sporadic incidence about 3 in one million (de Rubens Figueroa et al.2011) [4]. Especially, complete thoracic ectopia cordis in addition to complex heart disease, are known to have poor prognosis. (Sadlecki et al. 2011; Sakasai et al.2012) [4,5]. Surgical internalization of the heart into the thoracic cavity is associated with high risk of cardiovascular compromise and ischemia [5]. The paucity of survivors with this entity demonstrates the need for extreme caution in preserving hemodynamic stability when the heart is covered, whether the repair is performed as a primary or a staged repair.

\section{References}

[1] Cantrell, J. R., Haller, J. A., and Ravitch, M. M. 1958. “A Syndrome of Congenital Defects Involving the Abdominal Wall, Sternum, Diaphragm, Pericardium, and Heart.” Surg Gynecol Obstet 107: 602-14.

[2] De Rubens Figueroa, J., Sosa Cruz, E. F., Diaz Garcia, L., et al. 2011. "Cardiac Malformations in Patients with Pentalogy of Cantrell and Ectopia Cordis.” Rev Esp Cardiol 64: 615-8.

[3] Harring, G., Weil, J., Thiel, C., Schmelzle, R., and Mueller, G. C. 2015. "Management of Pentalogy of Cantrell with Complete Ectopia Cordis and Double Outlet Right Ventricle.” Congenital Anomalies 55: 121-3.

[4] Sadlecki, P., Krekora, M., Krasomski, G., et al. 2011. Prenatally Evolving Ectopia Cordis with Successful Surgical Treatment.” Fetal Diagn Ther 30: 70-2.

[5] Sakasai, Y., Thang, B. Q., Kanemoto, S., et al. 2012. Staged Repair of Pentalogy of Cantrell with Ectopia Cordis and Ventricular Septal Defect.” J Card Surg 27: $390-2$. 